\title{
Corporate Social Responsibility Perspectives in European Higher Education
}

DOI 10.18267/pr.2021.krn.4816.24

\author{
Vladimir Zhechev ${ }^{1}$ - Radka Nacheva ${ }^{2}$ - David Ríha ${ }^{3}$ \\ ORCID iD: 0000-0001-6677-9537¹, 0000-0003-3946-2416², 0000-0003-2481-9005³ \\ vladimir.zhechev@ue-varna.bg, r.nacheva@ue-varna.bg, david.riha@vse.cz \\ 1 University of Economics - Varna, Faculty of Management, Department of Marketing, \\ Varna, Bulgaria \\ 2 University of Economics - Varna, Faculty of Informatics, Department of Informatics, \\ Varna, Bulgaria \\ 3 Prague University of Economics and Business, Faculty of Business Administration, \\ Department of Marketing, Prague, Czech Republic
}

\begin{abstract}
Corporate social responsibility (CSR) takes a significant part of modern-day business organizations' decision making. Not only do companies have their performance assessed by CSR initiatives but also the former strive to strengthen their relationship with society by maintaining a distinctive sustainable corporate culture. Among the most widely adopted approaches for differentiation is the establishment of long-term relationships with customers, partners, employees, shareholders and civil society, among others. Universities are no exception. Modern higher education (HE) institutions place students at the center of the educational process, while maintaining personnel policies to motivate and retain a quality academic and administrative staff (especially given the pressure by the alternative sources of knowledge). In this respect, the aim of this paper is to investigate the opinions of $\mathrm{HE}$ representatives on five different dimensions of corporate social responsibility. We base our research on a methodology proposed by European Commission Directorate General for Enterprise.
\end{abstract}

Keywords: corporate social responsibility, higher education, human-centered management

JEL Classification codes: A22, C83, M14, M31

\section{INTRODUCTION}

Undisputedly the existence of every business organizations is determined (to a large extent) by meeting profit targets. However, many companies in 2021 are facing potential risks related to: skepticism towards demand, trade wars, eclipsing expansion plans due to the Corona virus economic crisis, change in tariff procedures, reprisal over imports (in some countries), redesigning supplier networks, internal restructuring just to name but a few. Meanwhile, to capture control over their value chain and maintain positive relationships with their existing customers, companies enact more socially responsible activities. Corporate social responsibility (CSR) aids not only in terms of fighting political unrest, the Covid-19 pandemic, and the aforementioned challenges, but also balances economic, social and ecological interests of communities.

As a matter of choice customers are witnessing a palpable shift towards their criteria for choosing a company to buy products and services from. The emergence of a segment of customers who are seeking sustainable production and delivery urges companies to level up 
their CSR policies and implement more viable solutions with greater care towards the environment and the communities.

These dynamics largely determine attraction, retention and sometimes cancellation of relationships between customers and companies. This creates new levels of concern for higher education institutions functioning in this business environment. Their most valuable assets the knowledge and skills they deliver to students - are accelerating towards a widening set of benefits related to the business environment. Namely, as businesses are seeking out socially responsible measures to attract the attention of publics, universities are imposing escalating focus on CSR in order to meet expectations and demands of the other stakeholders.

Higher education institutions have a profound role in every society. They are active members of a social ecosystem that competes against the modern-day challenges - responding to rapid changes in the economic, technological and political environment while promoting maintenance of long-term relationships with the civil society in every country. Currently HEIs are being placed under the CSR spotlight by ranking systems, accreditation procedures, student demands, local and international authorities' regulations, professional certification bodies and many others.

For all intents and purposes, modern-day universities now place corporate social responsibility at the heart of their activity by observing the interests of their students and disseminating the principles and results of CSR among broad public groups. This undoubtedly requires a change in the internal culture and values of HEIs next to care for the environment and achieving equilibrium of social interests related to building skills and competencies.

The aim of the paper is to propose a research methodology for studying the good practices of corporate social responsibility in higher education. It is based on the opinions of higher education representatives (having teaching and/or senior/executive decision-making roles) on five different dimensions of corporate social responsibility. These dimensions are: (1) workplace conditions; (2) environmental orientation; (3) business partnership engagement; (4) community engagement; (5) corporate values.

The objectives of the paper are:

(1) Review of literature on CSR perceptions, good practices and implementation in higher education;

(2) Proposing an research methodology for studying the current state of CSR orientation in different HEIs internationally;

(3) Summarizing the findings and proposition of further actions to reinforce the performance and reputation of higher education institutions in light of CSR.

The paper has several limitations among which: the study covers the opinions of individuals working in academia regardless of the profile of the higher education institution; probability sampling is used as a sampling method according to the availability of respondents; the research covers only the aforementioned five dimensions of CSR.

The paper analyzes CSR from the perspective of academics and decision-making personnel which gives (despite individual institutional logic) a good socioeconomic overview of the current state of CSR implementation in higher education. Understanding how CSR is seen and practiced can substantiate the benefits of motivating actions to pursue environmental, community-oriented and internal corporate value goals. This can be reflected both in educational curricula and in interactions with different stakeholders.

Higher education institutions may prioritize CSR in all its functions and across all its relationships as it can increase their international competitiveness and navigate the successful adaptation of their graduates with their future employers. Its manifold implementations can 
also ensure greater and faster efficiency in HEIs' integration into international economic and social ecosystems.

\section{LITERATURE REVIEW}

Higher education sees enormous shifts both in terms of modes of delivery and sources of differentiation in an ever-increasing competitive landscape. Universities attempt to enhance the preparation of students by organizing different initiatives with businesses, broadening career horizons, enlarging the integration of various social groups, and demonstration of the social responsibility of the institutions via activities related to: (1) environment protection; (2) maintaining sustainable relationships with business partners; (3) community engagement; (4) workplace conditions and corporate values (among others).

Corporate social responsibility holds the possibility to take higher education to another dimension in view of its competitive positions and in terms of its public image. This is especially valid in the current precarious times characterized by profound transformations related to restructuring of institutions, MOOCs, franchised programs, online modes of delivery and many other factors. Quintessentially, HEIs embrace CSR as part of their social role to increase the intellectual capital of nations by also adding value through creation of conditions for heightening of living quality standards and improvement of the environmental conditions people live and work in. The latter is inextricably linked but not limited to:

- Changing and amending curricula (Fernández Fernández \& Sanjuán, 2010);

- Institutional pressures by the public, students, governments (Rahman, Castka, \& Love, 2019);

- The perception of students, alumni and employers toward CSR (Sobczak, Debucquet, \& Havard, 2006);

- CSR as a predictor of job satisfaction and organizational commitment (Asrar-ul-Haq, Kuchinke, \& Iqbal, 2017).

Given the fact that the effectiveness of CSR is not solely dependent upon the efforts committed by higher education institutions, it is essential to review some of the factors, prerequisites and conditions upon which the former can yield positive results for the broader community. In view of this some authors investigate the CSR orientation of students and its predictors to identify stakeholder implications (Galvão, Mendes, Marques, \& Mascarenhas, 2019). Namely the authors have determined that religion, gender, program of study, political orientation and volunteerism impact the dimensions of CSR orientation. Other authors research whether social and demographic variables influence CSR perceptions and classify them into: pro CSR; resistant CSR, and secondary CSR (Teixeira, Ferreira, Correia, \& Lima, 2018). Alternatively, other source of literature take a differentiated perspective by using accreditation requirements (incorporating CSR) to evaluate quality performance of HEIs (Yeung, 2018).

Apart from being perceived as beneficial for all HEIs, CSR initiative can be pushed forward not only as a result of external requirements such as international ranking systems, accreditation standards, conditions for membership of professional organizations, etc. Academic and administrative staff have a significant role in nurturing and cultivating socially responsible actions of students and colleagues. Some of the preconditions for demonstrating these roles are related to job commitment, work satisfaction and involvement. In particular, staff members' engagement and organizational commitment in HEI have been studied as delivered by perceived CSR (Ahmad, Islam, \& Saleem, 2017). The study demonstrates that CSR positively influences both engagement and commitment of employees in higher education institutions. However, in order to achieve better, more structured and supportable results, HEIs must place a bigger emphasis on disseminating the results and other important outcomes of CSR activities in specialized reports (perhaps in a similar manner as the reporting of business 
organizations). Some scholars confirm that despite the increasing interest over sustainability, HEIs have been very sluggish in view of incorporating sustainability results in their general reporting systems (Sepasi, Braendle, \& Rahdari, 2019). This can hamper both multiplication of results and maintenance of competitive advantage on an international level. Yet students have their one role in mediating the effects of CSR in the home institutions to their future employers. Depending on the programme of study, students may be good ambassadors of CSR practices to their yet to come professional occupations. Studies show that one of the most central dimensions of CSR - environmental - has a very high attached importance by students in the field of business administration (tourism). The authors argue that CSR environmental practices can be significantly reinforced by higher level of education (Gligor-Cimpoieru, Munteanu, NițuAntonie, Schneider, \& Preda, 2017). On the other hand, choosing a potential company to work for is a choice of increasing complexity for current students. Not only do social benefits exert influence over their decision-making but also possible disproportion between personal and corporate values. In this regard research shows that CSR can be an important employment appeal factor for potential members of staff. One study found that students' assessment of corporate CSR practices and possible correspondence between own and business values can be essential sources of competitive advantage for companies that want to recruit talent.

The aforementioned sources of academic studies ascertain the high interest CSR has received as related to educational aims, corporate culture, community and social needs in order to integrate the efforts of different stakeholders towards a better, more sustainable future. This once again underlines that supreme importance that CSR holds on an educational level. More importantly higher education institutions can foster, develop and enrich the perceptions and implementation of CSR practices thus bridging together community, environmental, academic and employer interests (Zhechev \& Zhecheva, 2019). Some scholars even make a reference to the university role in CSR (formally called - University Social Responsibility - USR) from the point of view of teaching, learning and research output (Gómez, Pujols, Alvarado, \& Vargas, 2018).

Based on the studies reviewed and the most widely adopted principles of integration of CSR in higher education institutions we propose a methodology that builds upon the "Corporate Social Responsibility initiative of the European Commission Directorate-General for Enterprise" and adapt to serve the aim of our research.

\section{METHODOLOGY}

The purpose of this study is to outline a research methodology for investigating the opinion of academic staff representatives about corporate social responsibility policies that are applied to higher education institutions (Fig. 1). We suggest it is conducted in 5 stages, integrating of sociological, statical and machine learning methods and techniques. 
Fig. 1 Proposed Research Methodology

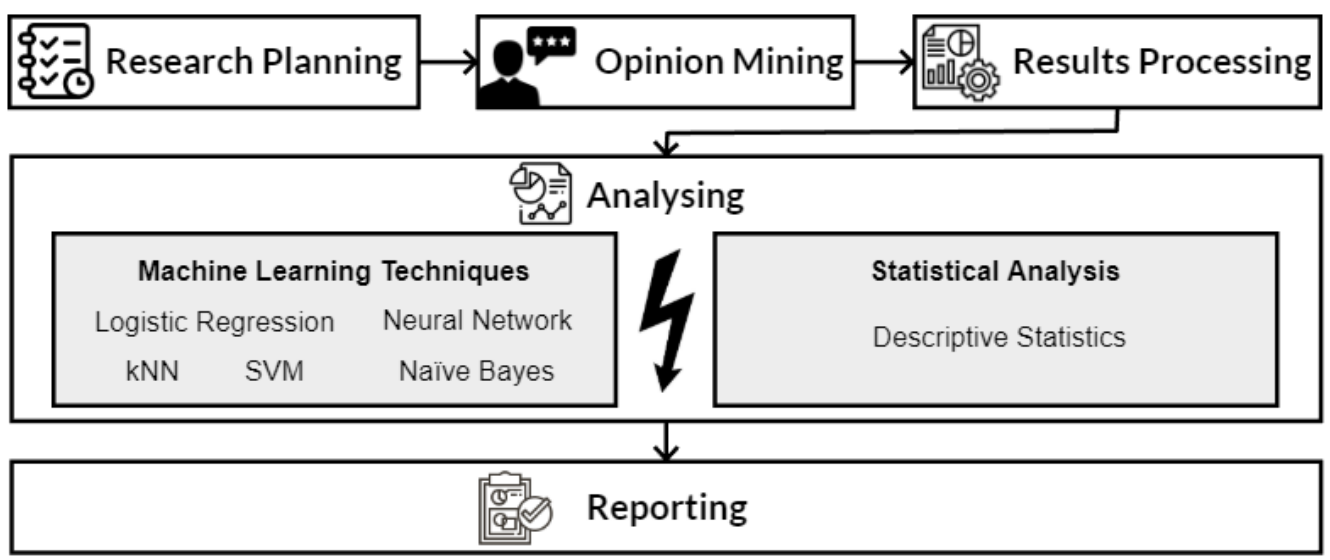

Source: own elaboration

The first phase of the methodology "Research Planning" is related to defining the goals and objectives of the research. It is necessary to define the dimensions of the study, which should cover good practices in corporate social responsibility in higher education. We integrated the framework of European Commission Directorate - General for Enterprise about Corporate Social Responsibility presented through awareness-raising questionnaire. It consists of five dimensions: Workplace Policies; Environmental Policies; Marketplace Policies; Community Policies and Institution Values. The European Commission's research framework is of general purpose. Some of the questions are not relevant for the purposes of our study and should therefore be adapted or eliminated altogether, mainly those related to Environmental Policies and Marketplace Policies. That is why we re-organized the survey by integrating a research finding of Freidenfelds, Kalnins and Gusca (2018) about the long-term environmental sustainability of HEIs. In addition, we proposed some new context-related questions.

We based the second "Opinion mining" stage on the methods of sociology for surveying the opinion of stakeholders. Specifically, we used our final suggested questionnaire (see Annex 1). Question codes are included that are used for the purposes of the analysis. They correspond to the main CSR dimensions.

The study used within-subject design, with the two main factors being the participants' academic position (Professor, Associate Professor, Chief Assistant Professor, Assistant Professor, Student) and hierarchical level in the institution (Employee, Executive, Middle Manager, Senior Manager, Student). The dependent variables were the ratings provided by the survey participants for each CSR policy in higher education context, as detailed Annex 1.

The "Opinion mining" stage went through the following workflow:

Firstly, developing an English questionnaire consisting of 3 main parts:

- General Information - it contained information about participants such as academic position, hierarchical level in the institution (if applicable), country of residence;

- Assessment of CSR HEIs policies - it was divided into 5 subgroups containing the CSR dimensions and related questions (see Annex1). A 5-level Likert scale were used: 1 Completely disagree, 5 - Completely agree, 0 - Not Applicable / Cannot answer;

- Closing remarks - participants share their recommendations on the successful implementation of corporate social responsibility at the higher education institutions.

Secondly, forwarding the questionnaire through variety of channels such as university internal communication environment, email and social networks (e.g., Facebook, ResearchGate and LinkedIn). 
The next phase "Results Processing" requires pre-processing of the results. It is mainly related to checking the free answer fields for texts entered in a language other than English.

The stage of "Analysing" is divided into two sub stages: analysis based on machine learning techniques and statistical analysis. It is related to the assessment of the results. The toolkit depends on the structure of the data extracted from the questionnaire - structured or not. We suggest the following machine learning techniques for the processing of the structured data from the questionnaire: Naïve Bayes, Support-vector machines (SVM), k-nearest neighbours (kNN), Logistic Regression and Neural Network. They are classification algorithms that are also used to predict research results.

The last phase of "Reporting" pays attention to the conclusions that can be drawn about the applied good practices for corporate social responsibility in higher education. They are summarized on the basis of the opinions expressed by the representatives of the academic community.

\section{RESULTS AND DISCUSSION}

The study involved 64 participants from the following countries: Czech Republic, Bulgaria, Russia, Germany, Poland, India, Egypt, Italy, United Kingdom. There were no invalid answers. One participant replied that she / he did not want her / his answers to be used for the purposes of the study. The percentage distribution of the respondents by academic positions and hierarchical level in the institution are shown on Fig. 2 and 3.

Fig. 2 Academic staff percentage

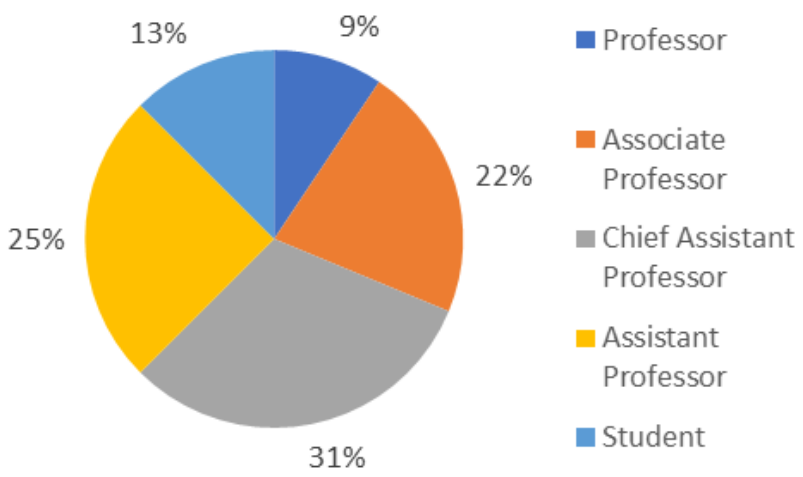

Source: own elaboration

Fig. 3 Hierarchical level percentage

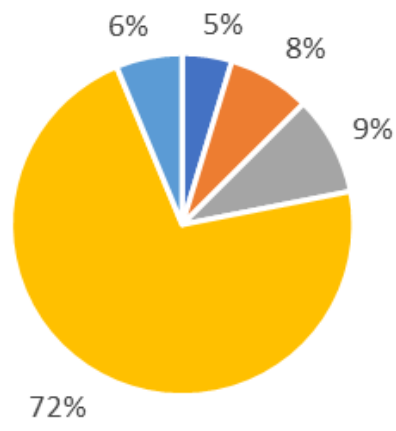

- Executive

- Senior

Manager

- Middle

Manager

- Employee

- Student

Source: own elaboration 
The alignment of the hierarchical levels in the institution by academic positions could be observed on Fig. 4.

Fig. 4 Dependence between hierarchical levels and academic positions

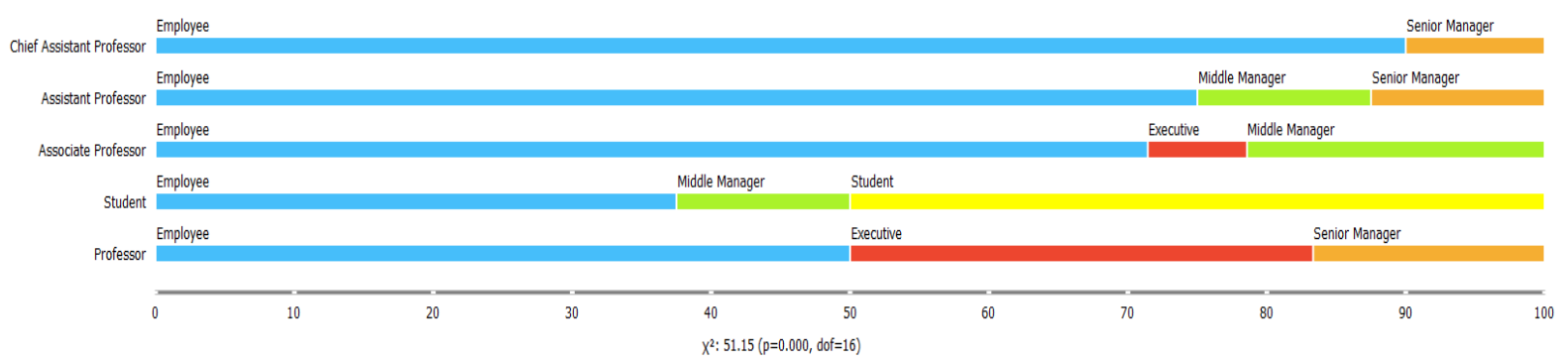

Source: own elaboration

It is noticeable that the percentage of employees who hold the positions of Associate Professor, Chief Assistant Professor and Assistant Professor, is the highest. The positions of Senior Manager and Middle Manager are held mainly by the aforementioned positions. Students are also engaged in administration. The share of participating professors is the smallest - only $9 \%$, of which one third are Executives.

In order to keep the analysis of data as simple as possible due to the large number of dependent variables, we present the results of the survey in summary form. Two main types of analysis were performed: statistical and based on machine learning techniques.

\section{Machine learning techniques}

It was used Orange Data Mining Tool for performing the machine learning techniques. The configuration of the Orange modules is shown on Fig. 5.

\section{Fig. 5 Machine learning Orange modules}

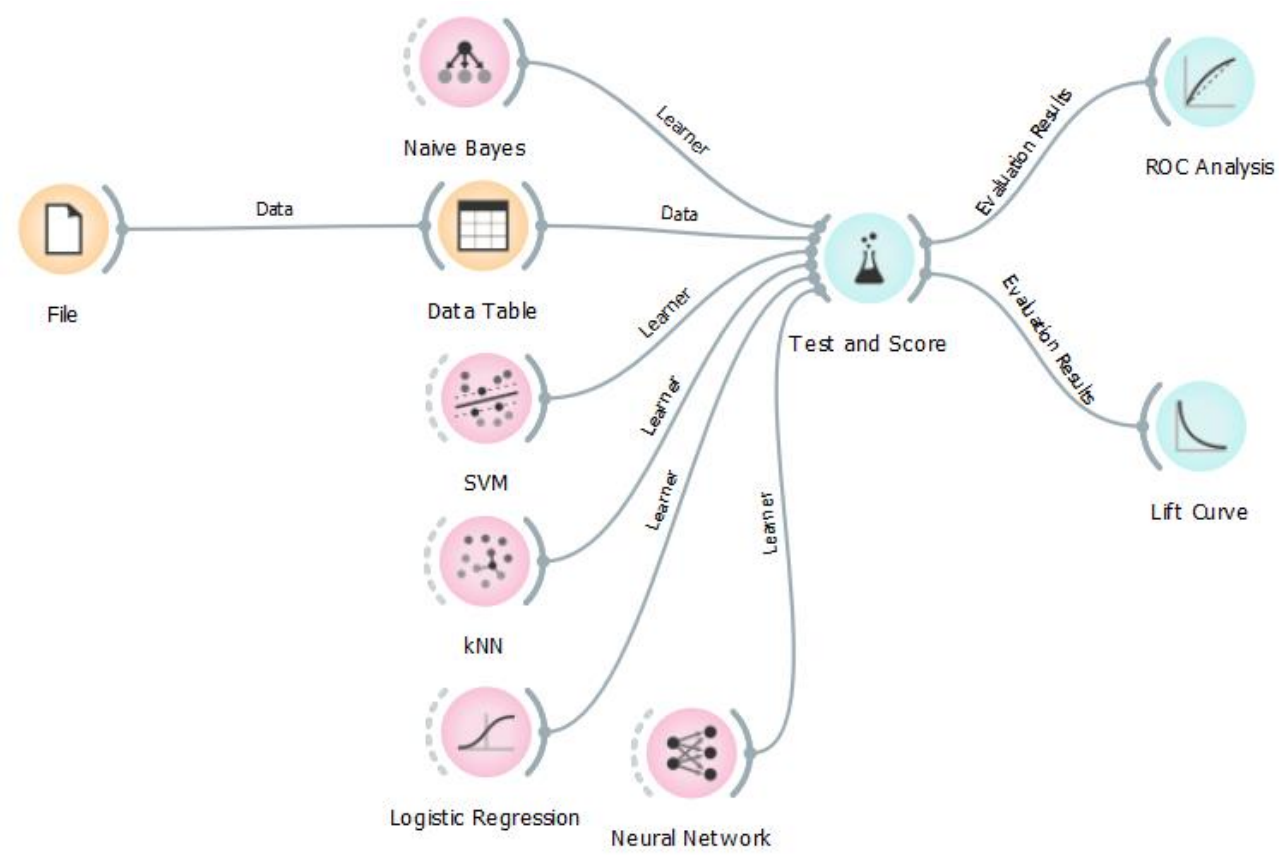


We applied: Naïve Bayes; SVM (settings: Polynomial kernel with numerical tolerance 0,001 were used); kNN (Euclidean metric was used); Logistic Regression and Neural Network (100 neurons in hidden layers and solver Adam were used). Testing and scoring were performed using Stratified 10 -fold cross validation on average over the target class which is the hierarchical institutional level of the participants. Table 1 summarizes the evaluation results. The following comparison criteria were used: Area under ROC (AUC); Classification accuracy (CA); F1; Precision and Recall.

Tab. 1 Machine learning algorithms results

\begin{tabular}{|l|l|l|l|l|l|}
\hline Model & AUC & CA & F1 & Precision & Recall \\
\hline kNN & 0,655 & 0,672 & 0,578 & 0,507 & 0,672 \\
\hline SVM & 0,393 & 0,703 & 0,593 & 0,513 & 0,703 \\
\hline Neural Network & 0,775 & 0,672 & 0,622 & 0,588 & 0,672 \\
\hline Naïve Bayes & 0,645 & 0,141 & 0,065 & 0,052 & 0,141 \\
\hline Logistic Regression & 0,615 & 0,688 & 0,643 & 0,659 & 0,688 \\
\hline
\end{tabular}

Source: own elaboration

The AUC values resulting from kNN, Naïve Bayes and Logistic Regression are close. They disclose low levels of implementation of social corporate responsibility policies in the educational institutions where participants work. According to the evaluation of the Neural Network the level of implementation of policies is satisfactory. SVM shows a low AUC value, which indicates that the algorithm generates negative research results. The numbers in the table cannot be considered unilaterally - only by AUC indicator. The values of the classification algorithms indicate that the most accurate are the results of SVM and Logistic Regression, followed by kNN and Neural Network. Unfortunately, the Naïve Bayes results cannot be taken into account due to the low values of CA, F1, Precision, Recall.

For this reason, we only consider the results of the Logistic Regression. A closer look at the analyses by hierarchical levels reveals that the executives gave the highest assessments of the CSR policies' implementation in the institutions managed by them. In second place are the grades of students, followed by employees, middle managers and senior managers. These are average estimates obtained on the basis of the answers of the representatives of different countries. Not all CSR policies are applicable to every institution, which implies a lack of feedback on some questions from the survey.

On the other hand, in order to be more precise in the analysis of the obtained data, we must also make a statistical analysis through which to broaden the scope of the research.

\section{Statistical analysis}

The descriptive statistics summarized by the five CSR dimensions in Table 2 are comparable to the conclusions we reached in the analysis of the data after applying the machine learning techniques. For all five dimensions, the executives gave the highest marks. However, the point of view of the lower hierarchical levels is interesting.

In contrast to the machine learning techniques we applied, in descriptive statistics, middle managers gave higher marks to the implementation of CSR policies than other levels. For example, the most common score for Workplace Policies and Marketplace Policies is 4, and for Institution Values it is the highest possible - 5. The other hierarchical levels have assigned 
lower grades. The most common assessment by senior managers is 3 for the implementation of policies in all five dimensions. Employees most often have given a rating of 2 for Community Policies and 4 for Institution Values. According to the students, Environmental Policies are not well represented in the universities where they study, judging by the low grades they have given for this dimension.

\section{Tab. 2 Descriptive statistics}

\begin{tabular}{|c|c|c|c|c|c|c|c|c|c|c|c|c|}
\hline \multirow{2}{*}{$\begin{array}{l}\text { Hierarchical } \\
\text { level }\end{array}$} & \multirow{2}{*}{ Indicator } & \multicolumn{5}{|c|}{ Dimension } & \multirow{2}{*}{$\begin{array}{l}\text { Academic } \\
\text { position }\end{array}$} & \multicolumn{5}{|c|}{ Dimension } \\
\hline & & D1 & D2 & D3 & D4 & D5 & & D1 & D2 & D3 & D4 & D5 \\
\hline \multirow{3}{*}{ Employee } & Mean & 3,170 & 2,393 & 3,358 & 2,379 & 3,454 & \multirow{3}{*}{$\begin{array}{l}\text { Assistant } \\
\text { Professor }\end{array}$} & 3,200 & 2,695 & 3,399 & 2,798 & 3,641 \\
\hline & SD & 1,452 & 1,713 & 1,653 & 1,656 & 1,601 & & 1,510 & 1,536 & 1,481 & 1,734 & 1,420 \\
\hline & Median & 3 & 3 & 4 & 2 & 4 & & 3 & 3 & 4 & 3 & 4 \\
\hline \multirow{3}{*}{ Executive } & Mean & 4,700 & 3,826 & 3,427 & 4,318 & 4,741 & \multirow{3}{*}{$\begin{array}{l}\text { Associate } \\
\text { Professor }\end{array}$} & 3,526 & 2,474 & 3,771 & 2,581 & 3,976 \\
\hline & SD & 0,433 & 1,443 & 1,430 & 0,697 & 0,404 & & 1,507 & 1,958 & 1,448 & 1,730 & 1,311 \\
\hline & Median & 5 & 5 & 5 & 5 & 5 & & 4 & 3 & 4 & 2 & 5 \\
\hline \multirow{3}{*}{$\begin{array}{l}\text { Middle } \\
\text { Manager }\end{array}$} & Mean & 3,402 & 2,711 & 3,917 & 3,247 & 4,507 & \multirow{3}{*}{$\begin{array}{l}\text { Chief } \\
\text { Assistant } \\
\text { Professor }\end{array}$} & 3,088 & 2,552 & 3,402 & 2,566 & 3,474 \\
\hline & SD & 1,149 & 1,203 & 1,007 & 1,452 & 0,592 & & 1,287 & 1,596 & 1,641 & 1,578 & 1,639 \\
\hline & Median & 4 & 3 & 4 & 3 & 5 & & 3 & 3 & 4 & 3 & 4 \\
\hline \multirow{3}{*}{$\begin{array}{l}\text { Senior } \\
\text { Manager }\end{array}$} & Mean & 3,210 & 2,687 & 2,669 & 2,479 & 3,147 & \multirow{3}{*}{ Professor } & 3,682 & 2,427 & 2,589 & 2,247 & 3,533 \\
\hline & SD & 1,415 & 1,354 & 1,349 & 1,442 & 1,177 & & 1,278 & 1,959 & 2,003 & 1,836 & 1,612 \\
\hline & Median & 3 & 3 & 3 & 3 & 3 & & 4 & 3 & 4 & 3 & 4 \\
\hline \multirow{3}{*}{ Student } & Mean & 2,850 & 1,934 & 2,731 & 2,922 & 2,667 & \multirow{3}{*}{ Student } & 2,896 & 1,957 & 2,683 & 2,576 & 2,690 \\
\hline & SD & 1,390 & 1,386 & 1,346 & 1,471 & 1,293 & & 1,335 & 1,333 & 1,349 & 1,396 & 1,388 \\
\hline & Median & 3 & 2 & 3 & 3 & 3 & & 3 & 2 & 3 & 3 & 3 \\
\hline \multirow{3}{*}{ Total } & Mean & 3,256 & 2,522 & 3,358 & 2,628 & 3,557 & \multirow{3}{*}{ Total } & 3,256 & 2,522 & 3,358 & 2,628 & 3,557 \\
\hline & SD & 1,413 & 1,666 & 1,605 & 1,638 & 1,522 & & 1,413 & 1,666 & 1,605 & 1,638 & 1,522 \\
\hline & Median & 3 & 3 & 4 & 3 & 4 & & 3 & 3 & 4 & 3 & 4 \\
\hline
\end{tabular}

Source: own elaboration

It is noteworthy that the representatives of the highest hierarchical level give the highest marks, while the representatives of the lower levels also express negative opinions through the low marks.

If we make an intersection of the results by academic positions (Table 2), we will notice differences in them obtained by division at hierarchical levels. The grades in general for all dimensions are 3 and 4 for the different positions. It is noted that the grades of assistant and chief assistant professors are identical for the five dimensions. Higher grades were given for Marketplace Policies and Institution Values. The lowest score was obtained by associate professors for Community Policies - 2. Once again, there is a tendency for higher positions to give higher ratings to CSR policies.

In a detailed review of descriptive statistics, we noticed that assistant and chief assistant professors have given low marks to the implementation of some individual policies. For example, policies D2-1e, D2-2b, D2-3b, D2-5d, D4-2a, D4-2b (see Annex 1) were mostly rated 
2. Policies D2-3e, D2-3h, D2-5c, D4-5a and D4-5b received mainly a score of 1 from the participants holding these two positions.

\section{CONCLUSION}

Based on the results obtained, we can conclude that the implementation of CSR policies in higher education is at an average level. The scores for some policies are 1 or 2 , which is indicative that institutions need to make more efforts to increase the satisfaction of their employees by providing them with a competitive development environment.

In the survey field for open answers, the participants, who hold the academic positions of assistant and chief assistant professor and are at the hierarchical level of an employee, have expressed some opinions on the implementation of CSR in higher education. For example, some of them are:

- $\quad$ "more green projects should be implemented involving students, in order to raise their awareness;

- use of own renewable energy sources, according to modern scientific technologies;

- since we deal each year with the new student group, clear green strategy communication is then a must;

- it would be better if my institution makes more for the nature and fights the pollution".

It is no coincidence that questions from dimensions D2 and D4 have received low marks.

Three participants have expressed the view that CSR policies were not adequately implemented in recruiting new employees, including concerns about discriminatory practices.

Opinions are not only negative $-26.56 \%$ of respondents expressed positive feedback on the organization of work in the institutions in which they work. They appreciate the results achieved during a pandemic in terms of the remote learning process; flexible working hours in academia; work safety; health insurance and medical care in the workplace.

Corporate social responsibility policies in higher education must be designed to be understood by all stakeholders - employees, students, partners, local community, suppliers, state administration. Employees and students must be trained on the importance of institutions' values and rules of conduct, but at the same time they must be provided with equal and fair opportunities for development.

\section{REFERENCES}

Ahmad, R., Islam, T., \& Saleem, S. S. (2017). Employee engagement, organizational commitment and job satisfaction as consequent of perceived CSR: A mediation model. Journal of Research Society of Pakistan, 55(2), 153-168.

Asrar-ul-Haq, M., Kuchinke, K. P., \& Iqbal, A. (2017). The relationship between corporate social responsibility, job satisfaction, and organizational commitment: Case of Pakistani higher education. Journal of Cleaner Production, 142, 2352-2363. https://doi.org/10.1016/j.jclepro.2016.11.040.

Fernández Fernández, J. L., \& Sanjuán, A. B. (2010). The presence of Business ethics and CSR in the higher education curricula for executives: the case of Spain. Journal of Business Ethics Education, 7, 25-38. https://doi.org/10.5840/jbee201073.

Freidenfelds, D., Kalnins, S. N., \& Gusca, J. (2018). What does environmentally sustainable higher education institution mean? Energy Procedia, 147, 42-47. https://doi.org/10.1016/j.egypro.2018.07.031. 
Galvão, A., Mendes, L., Marques, C., \& Mascarenhas, C. (2019). Factors influencing students' corporate social responsibility orientation in higher education. Journal of Cleaner Production, 215, 290-304. https://doi.org/10.1016/j.jclepro.2019.01.059.

Gligor-Cimpoieru, D. C., Munteanu, V. P., Nițu-Antonie, R. D., Schneider, A., \& Preda, G. (2017). Perceptions of future employees toward CSR environmental practices in tourism. Sustainability, 9(9), 1631. https://doi.org/10.3390/su9091631.

Gómez, L., Pujols, A., Alvarado, Y., \& Vargas, L. (2018). Social responsibility in higher educational institutions: An exploratory study. In The Goals of Sustainable Development (pp. 215-230). Springer. https://doi.org/10.1007/978-981-10-5047-3_13.

Rahman, A. A., Castka, P., \& Love, T. (2019). Corporate social responsibility in higher education: A study of the institutionalisation of CSR in Malaysian public universities. Corporate Social Responsibility and Environmental Management, 26(4), 916-928.

Sepasi, S., Braendle, U., \& Rahdari, A. H. (2019). Comprehensive sustainability reporting in higher education institutions. Social Responsibility Journal, 15(2), 155-170. https://doi.org/10.1108/SRJ-01-2018-0009.

Sobczak, A., Debucquet, G., \& Havard, C. (2006). The impact of higher education on students' and young managers' perception of companies and CSR: an exploratory analysis. Corporate Governance: The International Journal of Business in Society, 6(4), 463-474. https://doi.org/10.1108/14720700610689577.

Teixeira, A., Ferreira, M. R., Correia, A., \& Lima, V. (2018). Students' perceptions of corporate social responsibility: evidences from a Portuguese higher education institution. International Review on Public and Nonprofit Marketing, 15(2), 235-252. https://doi.org/10.1007/s12208018-0199-1.

Yeung, S. M.-C. (2018). Linking ISO 9000 (QMS), ISO 26000 (CSR) with accreditation requirements for quality indicators in higher education. Total Quality Management \& Business Excellence, 29(13-14), 1594-1611. https://doi.org/10.1080/14783363.2017.1282310.

Zhechev, V. S., \& Zhecheva, D. P. (2019). Ethical Branding: A Corporate Commitment Or Compliance With Contemporary Trends. Annals of Marketing-Mba, 4, 72-90.

\section{ANNEX 1. CORPORATE SOCIAL RESPONSIBILITY QUESTIONNAIRE}

\begin{tabular}{|l|l|}
\hline Question & Code \\
\hline Dimension1: Workplace Policies & D1 \\
\hline $\begin{array}{l}\text { The institution implement policies to encourage real skills development of employees via } \\
\text { supporting: }\end{array}$ & D1-1 \\
\hline a. [Performance appraisal process] & D1-1a \\
\hline b. [Training plan] & D1-1b \\
\hline $\begin{array}{l}\text { The institution implement policies to encourage long-term career development of } \\
\text { employees via supporting: }\end{array}$ & D1-2 \\
\hline a. [Performance appraisal process] & D1-2a \\
\hline b. [Training plan] & D1-2b \\
\hline $\begin{array}{l}\text { There is a process to ensure adequate steps are taken against all forms of discrimination, } \\
\text { both in the workplace and at the time of recruitment (e.g. against women, ethnic groups, } \\
\text { disabled people, etc.). }\end{array}$ & D1-3 \\
\hline $\begin{array}{l}\text { There are consultations of the employees on issues important for them (for example, } \\
\text { holding an academic position, raising the qualification, professional development, etc.). }\end{array}$ & D1-4 \\
\hline $\begin{array}{l}\text { Your institution have suitable arrangements for health, safety and welfare that provide } \\
\text { sufficient protection for the employees. }\end{array}$ & D1-5 \\
\hline
\end{tabular}




\begin{tabular}{|c|c|}
\hline Question & Code \\
\hline $\begin{array}{l}\text { Your institution actively offer a good work-life balance for its employees, for example, by } \\
\text { considering flexible working hours or allowing employees to work from home. }\end{array}$ & D1-6 \\
\hline Dimension2: Environmental Policies & D2 \\
\hline $\begin{array}{l}\text { Please indicate which of the following environmental policies is applicable to the } \\
\text { institution you represent. }\end{array}$ & D2-1 \\
\hline a. [Energy conservation] & D2-1a \\
\hline b. [Waste minimisation and recycling] & D2-1b \\
\hline C. [Pollution prevention] & D2-1c \\
\hline d. [Protection of the natural environment] & D2-1d \\
\hline e. [Sustainable transport options] & D2-1e \\
\hline Your institution save money by reducing its environmental impact. & D2-2 \\
\hline a. [Reducing energy consumption] & D2-2a \\
\hline b. [Preventing pollution] & $D 2-2 b$ \\
\hline Your institution considers the potential environmental impacts of organizing its activities. & D2-3 \\
\hline a. [Heat energy produced/consumed per person] & D2-3a \\
\hline b. [Heat energy produced/consumed per square meter] & D2-3b \\
\hline c. [Amount of electricity generated/consumed per person] & D2-3C \\
\hline d. [Amount of electricity generated/consumed per square meter] & D2-3d \\
\hline e. [CO2 emissions per person (e.g. student, administrative and scientific personnel)] & D2-3e \\
\hline f. [Cold/hot water consumption per person] & D2-3f \\
\hline g. [Cold/hot water consumption per square meter] & $\mathrm{D} 2-3 \mathrm{~g}$ \\
\hline h. [Environmentally friendly vehicles usage] & D2-3h \\
\hline Your institution supply clear and accurate environmental information on its activities to: & D2-4 \\
\hline a. [Students] & D2-4a \\
\hline b. [Employees] & $\mathrm{D} 2-4 \mathrm{~b}$ \\
\hline c. [Local community] & D2-4C \\
\hline There are environmental policies undertaken by the management of your institution. & D2-5 \\
\hline \begin{tabular}{|l} 
a. [Initiatives in the field of resource consumption reduction (e.g. thermal energy, \\
electricity, transport, water consumption and waste management)]
\end{tabular} & D2-5a \\
\hline $\begin{array}{l}\text { b. [Investment volume for improvement of energy efficiency of buildings, to reduce water } \\
\text { consumption, heat loss prevention] }\end{array}$ & D2-5b \\
\hline c. [Initiatives for the use of more environmentally friendly transport] & D2-5C \\
\hline d. [Green procurement procedures] & D2-5d \\
\hline Dimension3: Marketplace Policies & D3 \\
\hline $\begin{array}{l}\text { Your institution have a policy to ensure honesty and quality in all its contracts, dealings } \\
\text { and advertising (e.g. provisions for consumer protection, etc). }\end{array}$ & D3-1 \\
\hline Your institution provide clear and accurate information about its services. & D3-2 \\
\hline \begin{tabular}{|l} 
Your institution ensure equality in sustaining relationships with stakeholders. \\
\end{tabular} & D3-3 \\
\hline a. [Students] & D3-3a \\
\hline b. [Employees] & D3-3b \\
\hline c. [Suppliers] & D3-3c \\
\hline d. [Partners] & D3-3d \\
\hline e. [State administration] & D3-3e \\
\hline f. [Local community] & D3-3f \\
\hline $\begin{array}{l}\text { Your institution support a process to ensure effective feedback, consultation and/or } \\
\text { dialogue with: }\end{array}$ & D3-4 \\
\hline a. [Students] & D3-4a \\
\hline b. [Employees] & D3-4b \\
\hline c. [Suppliers] & D3-4c \\
\hline d. [Partners] & D3-4d \\
\hline
\end{tabular}




\begin{tabular}{|c|c|}
\hline Question & Code \\
\hline e. [State administration] & D3-4e \\
\hline f. [Local community] & D3-4f \\
\hline Your institution register and resolve complaints from: & D3-5 \\
\hline a. [Students] & D3-5a \\
\hline b. [Employees] & D3-5b \\
\hline c. [Suppliers] & D3-5C \\
\hline d. [Partners] & D3-5d \\
\hline e. [State administration] & D3-5e \\
\hline f. [Local community] & D3-5f \\
\hline $\begin{array}{l}\text { Your institution work together with business or other organisations to address issues } \\
\text { raised by responsible entrepreneurship. }\end{array}$ & D3-6 \\
\hline Dimension4: Community Policies & D4 \\
\hline Your institution offer training opportunities to people from the local community: & D4-1 \\
\hline a. [Internships for scholars] & D4-1a \\
\hline b. [Internships for students] & D4-1b \\
\hline c. [Work experience for students] & D4-1C \\
\hline d. [Internships for disadvantaged groups] & D4-1d \\
\hline e. [Work experience for disadvantaged groups] & D4-1e \\
\hline $\begin{array}{l}\text { Your institution have an open dialogue with the local community on adverse, } \\
\text { controversial or sensitive issues that involve it related to: }\end{array}$ & D4-2 \\
\hline a. [Accumulation of waste outside its premises] & D4-2a \\
\hline b. [Vehicles obstructing roads] & $\mathrm{D} 4-2 \mathrm{~b}$ \\
\hline c. [Footpaths] & D4-2C \\
\hline Your institution is trying to support business activities locally? & D4-3 \\
\hline $\begin{array}{l}\text { The employees are encouraged to participate in local community activities (e.g. providing } \\
\text { employee time and expertise, or other practical help)? }\end{array}$ & D4-4 \\
\hline $\begin{array}{l}\text { Your institution give regular (financial) support to local community activities and projects } \\
\text { which are expressed in: }\end{array}$ & D4-5 \\
\hline a. [Charitable donations] & D4-5a \\
\hline b. [Sponsorship] & $\mathrm{D} 4-5 \mathrm{~b}$ \\
\hline c. [Providing facilities for holding events] & D4-5C \\
\hline Dimension5: Institution Values & D5 \\
\hline Your institution's values and rules of conduct are clearly defined. & D5-1 \\
\hline The institution's values communicate correctly to: & D5-2 \\
\hline \begin{tabular}{|l|} 
a. [Students] \\
\end{tabular} & D5-2a \\
\hline b. [Employees] & D5-2b \\
\hline c. [Suppliers] & D5-2c \\
\hline d. [Partners] & D5-2d \\
\hline e. [State administration] & D5-2e \\
\hline f. [Local community] & D5-2f \\
\hline The students are aware of your institution's values and rules of conduct. & D5-3 \\
\hline The employees are aware of your institution's values and rules of conduct. & D5-4 \\
\hline $\begin{array}{l}\text { The employees are trained on the importance of your institution's values and } r \\
\text { conduct. }\end{array}$ & D5-5 \\
\hline
\end{tabular}

